\title{
THE COMMERCIAL VALUATION PROCESS: TASK ORDER, PERSONNEL AND CONSULTATION

\author{
TIM HAVARD
} \\ University of Salford
}

\begin{abstract}
Behavioural studies into valuation and appraisal have to be undertaken with as full an understanding of the context and framework of the process as possible in order to be realistic. Although there is general knowledge about the commercial valuation process from anecdotal information, there is little hard information about how valuations are actually carried out in the field and that this is a major gap in the knowledge base that will hinder future behavioural research. The paper reports the results of an empirical study into commercial valuation practice which provides valuable information on task ordering, personnel and consultation occurring during typical commercial instructions.
\end{abstract}

Keywords: Commercial valuation, practice, behaviour.

\section{INTRODUCTION}

A recent RICS research paper (Baum et al, 2000) has highlighted some of the potential for client influence to affect the independence of commercial valuations. This work compliments a growing body of work related with human cognition and decision-making that examines areas where human behaviour can lead to bias in the outcome of the valuation process (Diaz, 1997; Gallimore and Wolverton, 2000; Havard, 2002). The common theme to this body of research is that the behaviour of individuals has been shown to result in biased or sub-optimal valuations.

Newell and Simon (1972), working in the field of human cognition and decisionmaking, observed that decision-making tasks were a connected process of information processing, task environment comprehension and problem space definition. The actual task is thus not the only consideration in behavioural studies, but the process as a whole and the environment in which the task takes place must also be considered. An important element of analysing a valuation as a decisionmaking process must include a comprehensive understanding of how the process is actually undertaken.

Although the residential appraisal process has been examined in the US (Diaz, 1990) and the UK and New Zealand (Diaz et al, 2000), the commercial valuation process remains largely undescribed. In the USA, the principal text books, for example, the Appraisal Manual ( $9^{\text {th }}$ Edition) does lay down the major steps in the 
valuation process that an appraiser should follow. Similarly, UK valuation texts such as the Income Approach to Property Valuation (Baum, Mackmin and Nunnington, 1998) describe the components of the process. The Valuation and Appraisal Manual of the RICS (2003) in the UK provides considerable guidance to the valuer as to the conduct of the valuation and lays down a number of mandatory requirements and considerations that a competent valuer must take, but it is not prescriptive as to the actual form of the valuation.

There are no empirical studies in the commercial valuation field as to how the process is actually undertaken in the UK. Information on this is vital to the production of meaningful behavioural studies. This study attempts to redress this gap in the knowledge.

\section{AIMS AND OBJECTIVES}

The research reported here concentrates on components of the actual conduct of the commercial valuation. It examines three areas that are of significance to the workings of the process that leads to a commercial valuation. These three areas are:

(i) The order of task completion

(ii) The personnel involved in carrying out the sub-tasks within a valuation

(iii) The people consulted during a valuation and the points in the process when that consultation takes place.

Establishing the task order is very important in understanding how valuers arrive at their opinion of value. The task order illustrates how valuers receive information. In other research, the sequence of information has been shown to influence opinionforming in uncertain situations (for example, Assere, 1992; Ashton and Ashton, 1988, 1987; Messier, 1992; Chan, 1995; Hogarth and Einhorn, 1992; Pei et al, 1992; Krull et al, 1993; Tubbs, 1990). Establishing task order from a sample of valuers will also provide information about the degree of variation in behaviour across commercial valuation practice, giving some understanding of the rigour of the process.

An investigation of the personnel involved in a commercial valuation is also very important in a behavioural study. One of the main problems in undertaking behavioural analysis in commercial valuation is that all the tasks are rarely conducted by a single individual, although a single individual is usually responsible for the overall conduct of the valuation. This greatly increases the complexity of analysis required to understand the behavioural influences on the process. The majority of behavioural studies examine the behaviour of the individual in decisionmaking and not the complex interaction of many personnel with different levels of seniority and influence. Mapping of the personnel involved in the task activity is an 
essential step to understanding the behavioural influences on the outcome of the valuation process.

When considering the valuation of a single commercial property (as opposed to a portfolio), there are five main options available in terms of the identity of the personnel carrying out the work:

(a) The valuation is conducted by a single valuer working alone. Anecdotal evidence prior to this research suggested that this is rare, being mainly confined to smaller firms;

(b) The valuation is conducted by a senior valuation professional assisted by a junior associate;

(c) The valuation is conducted by a senior valuation professional with delegation of some tasks to a junior associate;

(d) The valuation instruction is agreed by a senior valuation professional with delegation of the majority of tasks to a junior associate. In this mode, the senior valuer tends only to be substantially involved at the beginning and end of the process

(e) The valuation is conducted in its entirety by junior members of the firm.

There are strengths and weaknesses in each approach, and there is clearly scope for blurring at the margins, but this is a reasonable framework for analysing the personnel involved in a commercial valuation.

If the personnel involved in a valuation is an important consideration, then clearly who they consult during that process is equally important. Each consultation a valuer makes is a point where the outcome of a valuation may be affected. Consultation also represents a key stage in collecting the information that the valuer uses to arrive at their final answer. Three areas were examined:

(a) Who do valuers consult during a valuation?

(b) At what point in the valuation process does that consultation take place?

(c) How frequently does consultation take place?

The collection of information on these three components of the valuation process will greatly add to the understanding of the decision-making process that results in a commercial valuation.

\section{METHODOLOGY}

The research took the form of a structured interview utilising a questionnaire.

The questionnaire was structured to enable both the maximising of data collection from the interviewees and simplifying the later analysis. The questionnaire 
consisted of a range of open and closed questions, with some of the latter allowing boxes to be ticked to indicate the appropriate response, either by the interviewer or the interviewee. The latter occurred where the question dealt with the more complex areas of procedure. The interviewees received an extract from the questionnaire that contained these particular questions and the appropriate answer sheet. These were collected at the end of the interview. The interviews were taped with the permission of the interviewees for later transcription.

The interviews took place at the office of the interviewees. No fee was paid to the participants.

\section{SAMPLING STRATEGY}

The sample selected were chartered surveyors working for private practice chartered surveying firms in the north-west of England and was carried out in the first part of 2000. A further sample using the same methodology was collected in early 2004 to check whether there had been any significant changes in practice in the ensuing period. No significant changes were noted and the findings of the original survey were found to be still valid. The sample size was not specifically defined other than it was to represent more than half of the firms carrying out valuation work within the region (by number of firms, not instructions). A nonprobability sampling approach was selected as being most appropriate; i.e. the interviewees were selected according to the frequency in which their firms carried out commercial valuation work (see Kidder (1981) for a discussion on purposive sampling). The justification of the above is that this research was largely qualitative rather than quantitative. "Qualitative researchers usually work with small samples of people, nested in their context and studied in depth - unlike quantitative researchers who aim for large numbers of context stripped cases and seek statistical significance" (Miles and Huberman, 1984).

Notwithstanding this, there were a number of factors to consider in the selection of the sample. These will be discussed in the section below. Defining the sample was relatively simple in terms of the personnel, but less straightforward for other aspects. As noted, the sampling concentrated on obtaining responses from the most senior members of the profession. Although valuations are carried out by chartered surveyors within a range of organisations, the majority are carried out within private practice surveying firms. It was decided to draw the sample only from this group.

The choice of the geographical location of this sample created some practical difficulties in drawing interviewees from a sample of the larger individual offices. The original intention of the sampling strategy was to obtain as full a coverage as possible of all the firms carrying out regular commercial valuation work within a single region; in this case, the north west of England. The rationale behind this was that this would allow observations to be made regarding all types and sizes of firms 
carrying out valuation work. Clearly, the structure and procedure in a small firm was likely to be different from that that existed in a larger firm where specialist valuers might exist. Similarly, the practice and procedure in a regional firm might differ from that adopted from a national or international practice.

Within the North West region of the UK, Manchester is the largest commercial centre; indeed, it is the largest commercial centre outside London ${ }^{1}$. The second major commercial centre in the region is Liverpool, whilst there are also substantial commercial property markets in Warrington, Preston and Chester. Commercial surveying practices were identified using both the RICS directory for the North West and the most current Estates Gazette directory. The firms were contacted by telephone to establish whether they undertook a substantial amount of commercial valuation work ${ }^{2}$. The firms were then contacted by letter which explained the purpose of the research, the type of assistance required and a request that an interview with the head of commercial valuation or senior valuation surveyor be arranged. 40 firms were approached in Manchester and 21 interviews resulted. 21 firms in Liverpool were contacted which resulted in six interviews, whilst 35 firms in the smaller centres of Chester, Warrington, Preston, Blackburn, Bolton and Lancaster were approached. These resulted in only five interviews, of which two were not included in the final analysis because it was felt that the interviewee were working in too specialised an area or else carrying out insufficient commercial valuation work.

Two factors became clear from the initial sampling. The first was that there was a concentration of valuations being undertaken in the large metropolitan cities, with relatively little substantial capital valuation work being done outside of Manchester and Liverpool. A common response to the initial approach from a number of the smaller practices in the region was that they had ceased to do valuation work because they did not find it to be cost effective. This observation is anecdotal as no formal data was collected on this area.

An implication of this is that, although the interview sample represents only around $19 \%$ of the total population of commercial surveyors operating within the study area, it is a substantial sample of the firms doing a significant amount of commercial valuation work in the region. It is impossible to accurately determine what percentage of commercial valuations carried out in the North West are carried out by the firms interviewed. The preliminary telephone contact mentioned above suggested that there were around 45-50 firms regularly carrying out commercial valuations in the areas sampled. The interview population of 30 (i.e. excluding the

\footnotetext{
${ }^{1}$ In terms of the number of commercial firms with registered addresses in the city

${ }^{2}$ This was defined for the purpose of sampling as "regularly carrying out capital valuations of freehold or long leasehold retail, office or industrial buildings for any purpose"
} 
two firms mentioned above) may, therefore, represent $60-70 \%$ of the total population.

Table 1: Details of the original sample selection

\begin{tabular}{cccccc}
\hline Location & $\begin{array}{c}\text { Number of } \\
\text { Surveying } \\
\text { Firms in } \\
\text { Estates } \\
\text { Gazette } \\
\text { Directory }\end{array}$ & $\begin{array}{c}\text { Number } \\
\text { Contacted }\end{array}$ & $\begin{array}{c}\text { Percentage } \\
\text { of Total } \\
\text { Firms } \\
\text { Listed in } \\
\text { Directory }\end{array}$ & $\begin{array}{c}\text { Number } \\
\text { Interviewed }\end{array}$ & $\begin{array}{c}\text { Percentage } \\
\text { of Total } \\
\text { Firms } \\
\text { Listed in } \\
\text { Directory }\end{array}$ \\
\hline Manchester & 93 & 40 & $43.01 \%$ & 21 & $22.58 \%$ \\
Liverpool & 25 & 21 & $84.00 \%$ & 6 & $24.00 \%$ \\
$\begin{array}{c}\text { Chester, } \\
\text { Warrington, } \\
\text { Preston, } \\
\text { Blackburn, } \\
\text { Bolton and } \\
\text { Lancaster }\end{array}$ & 52 & 35 & $67.31 \%$ & 5 & \\
\hline TOTAL & 170 & 96 & $56.47 \%$ & 32 & \\
\hline
\end{tabular}

A second factor that became clear was that the strategy of collecting data from within the region alone meant that very little data was to be collected from the very largest of practices where the office structures allowed even more specialisation. Because of this second factor, it was decided to obtain a sample from the larger London practices to fill the gap in the data. 30 firms in London were contacted in the same way as has been described above, with a target of obtaining 10 interviews which was achieved.

That the sample was not drawn from a single geographical region was not felt to be significant for the majority of the study. One of the main purposes of the study was to establish practice and procedure in commercial valuation in the UK. As noted, it was anticipated that there were some variations according to the size, structure and character of the firms carrying out the valuation work. It was these variations that the study set out to capture; hence it was felt to be more important to draw a range of responses from a range of organisations than to continue to draw the sample from a single region.

It was anticipated that the structure of the office was likely to be dependent on the office size. With smaller offices with less than 10 professional staff, no specialisation into departments would occur. In these firms, it was anticipated that 
a person doing valuations would also carry out other work, including agency work, that gave direct exposure to the market. There would, however, be less opportunity to consult with others during the valuation and access to data may be reduced. At the other end of the scale, in the very large offices with more than 40 staff, it was likely that much more specialisation occurred. A valuer here would probably only do valuation work and have no direct exposure to the actual market. Clearly, the consultation and information flow structure would be rather different. In between these extremes, there are a large number of medium sized firms that may show attributes of each.

Table 2: Geographical breakdown of interview sample

\begin{tabular}{lrcc}
\hline Location & Total & $\begin{array}{c}\text { UK } \\
\text { National }\end{array}$ & $\begin{array}{c}\text { UK } \\
\text { Regional }\end{array}$ \\
\hline Manchester & 21 & 16 & 5 \\
North West Region $^{3}$ & 9 & 0 & 9 \\
London & 10 & 9 & 1 \\
\hline TOTAL & 40 & 25 & 15 \\
\hline
\end{tabular}

Because of these expectations about organisations, it was important to obtain a balanced sample of firm size as noted above. A breakdown of the sample of office sizes against the type of firm (national or regional) is illustrated in Table 2.

Table 3: Analysis of office size in which the interviewees worked against the type of firm

\begin{tabular}{lccc}
\hline Office Size (number of staff) & Occurrence & National Firms & $\begin{array}{c}\text { Regional } \\
\text { Firms }\end{array}$ \\
\hline$<10$ & 11 & 3 & 8 \\
$10-40$ & 19 & 14 & 5 \\
$>40$ & 10 & 8 & 2 \\
\hline TOTAL & 40 & 25 & 15 \\
\hline
\end{tabular}

The interview research was targeted at senior members of the profession. Senior professionals would be expected to have a greater experience of valuation practice and procedure. They would also have a greater knowledge base regarding observation of valuation variance of errors in valuation in practice. In particular,

\footnotetext{
${ }^{3}$ Note that the original intention was to classify the data by Manchester and Liverpool and the rest of the North west. It became clear that the number of firms surveyed in rest of the North west and Liverpool was very small and that the firms in Liverpool had more of the characteristics of the region as a whole than those of Manchester. The latter was the favoured location of regional offices of national firms whose headquarters were in London. Because of these two factors, it was decided to include the Liverpool sample within that of the North west region.

Pacific Rim Property Research Journal, Vol 11, No 1 
they would be able to provide a strategic overview of the organisation of their firm and office.

This target was generally achieved. Of the interviewees, 39 were male and 1 was female. The mean age was 42.875 (SD 8.468 years). The type of position held by the interviewees is illustrated in Table 4 . Some $70 \%$ of the interviewees were at salaried partner or director level or above ${ }^{4}$.

Table 4: Position in firm held by interviewee

\begin{tabular}{lr}
\hline Position Held & No. \\
\hline Professional Staff & 3 \\
Associate & 9 \\
Salaried Partner/Director & 16 \\
Equity Partner & 10 \\
Senior Partner & 0 \\
Sole Trader & 2 \\
\hline Total & 40 \\
\hline
\end{tabular}

A final requirement of the sample was that it should be drawn from a population who frequently carried out commercial valuation work. Between the group, the sample was responsible for carrying out around 4300 capital valuations per annum.

Table 5: Analysis of the type of work carried out by the interviewees

\begin{tabular}{lccccc}
\hline $\begin{array}{c}\text { Commercial } \\
\text { valuations } \\
(\%)\end{array}$ & $\begin{array}{c}\text { \% of work } \\
\text { reported by } \\
\text { interviewees }\end{array}$ & $\begin{array}{c}\text { Desk } \\
\text { valuations } \\
(\%)\end{array}$ & $\begin{array}{c}\text { \%o of work } \\
\text { reported by } \\
\text { interviewees }\end{array}$ & $\begin{array}{c}\text { Types of } \\
\text { property } \\
\text { valued }\end{array}$ & $\begin{array}{c}\text { Mean \% of } \\
\text { work } \\
\text { reported by } \\
\text { interviewees }\end{array}$ \\
\hline Mean & 97.5 & Mean & 28.5 & Retail & 33.24 \\
Min & 90 & Min & 0 & Office & 30.00 \\
Max & 100 & Max & 80 & Industrial & 35.82 \\
Median & 100 & Median & 17.5 & & \\
\hline
\end{tabular}

As can be observed from Table 5, the sample population were almost exclusively undertaking commercial valuation work, with the highest percentage of noncommercial work being reported by any of the respondents being $10 \%$. The

\footnotetext{
4 A number of firms interviewed had incorporated whilst the remainder retained the traditional partnership structure. The decision to incorporate does not seem to make a material difference to the operational structure of the firms and no distinction is made between companies and partnerships in the analysis.
} 
interviewees were mainly carrying out new rather than update valuations. The respondents dealt with a fairly balanced range of property types.

In conclusion, the interviewee programme aimed to gather data from a representative sample of senior commercial valuers drawn from a variety of types and size of firms operating within the North West of England. These included both regionally based firms and local offices of national and international real estate consultancies. In general, this was achieved with the exception that firms with larger offices and thus more complex internal structures were not represented in the initial sample. With the addition of a sample of larger firms drawn from London (in this case, all international real estate practices), a more balanced sample was achieved. The 40 interviewees represent approximately 780 man-years of experience. The data obtained should be representative of practice in the UK today due to the quality of this sample.

\section{RESEARCH FINDINGS}

\section{Sequencing of task completion}

An investigation of the literature on commercial valuation could not identify an order of task sequencing; however, 14 key tasks were identified from a review of valuation texts and also from preliminary interviews with practitioners (these preliminary interviews are not included within the main study). The participants were asked to indicate the order in which they carried out the 14 task activities identified. The results are presented as Figure 1 below.

As can be observed, a contour map of sequencing has been constructed on Figure 1 illustrating the dominant sequence of activities and the activities that illustrated the greatest variation in sequencing. There was no statistically significant variation in sequencing found between small, medium and large firms.

This analysis has enabled a typical sequence of the 14 key activities to be established using the mean score and the modal class. This analysis reveals that some activities tend to occur simultaneously. This was confirmed by ANOVA and the Fisher LSD analysis which showed that the means were significantly different, except for the economic assessment of location and collection of comparable evidence and the three analysis tasks where the null hypothesis that the means were not identical could not be rejected. This reveals that there are 10 groups of activities in a typical commercial valuation. This is illustrated in Table 7.

A number of key observations can be made about task ordering. Only at the beginning and end of the valuation process was the task sequence uniform across the sample of valuers indicated. There was a relatively wide degree of variation in sequence noted after the agreement of instructions to the actual calculation of capital value, though a common path could be determined. 
Figure 1: Sequence of key task completion as reported by interviewees

\begin{tabular}{|c|c|c|c|c|c|c|c|c|c|c|c|c|c|c|}
\hline $\begin{array}{l}\text { Sequence of } \\
\text { activities }\end{array}$ & 1 & 2 & 3 & 4 & 5 & 6 & 7 & 8 & 9 & 10 & 11 & 12 & 13 & 14 \\
\hline \multicolumn{15}{|l|}{ Activity } \\
\hline $\begin{array}{l}\text { Issue and } \\
\text { agreement of } \\
\text { instructions }\end{array}$ & $93 \%$ & & & & & & & & & & $3 \%$ & $5 \%$ & & \\
\hline $\begin{array}{l}\text { Analysis/scrutiny } \\
\text { of legal } \\
\text { documentation }\end{array}$ & $0 \%$ & $11 \%$ & & $18 \%$ & $3 \%$ & $32 \%$ & $21 \%$ & $5 \%$ & & $8 \%$ & & & $3 \%$ & \\
\hline $\begin{array}{l}\text { Inspection of the } \\
\text { property }\end{array}$ & $3 \%$ & $73 \%$ & $20 \%$ & $5 \%$ & & & & & & & & & & \\
\hline $\begin{array}{l}\text { Measurement of } \\
\text { the property }\end{array}$ & $2 \%$ & $68 \%$ & $22 \%$ & $7 \%$ & & & & & & & & & & \\
\hline $\begin{array}{l}\text { Economic } \\
\text { assessment of } \\
\text { location }\end{array}$ & & $10 \%$ & $7 \%$ & $29 \%$ & $41 \%$ & $5 \%$ & $5 \%$ & & $2 \%$ & & & & & \\
\hline $\begin{array}{l}\text { Collection of } \\
\text { comparable } \\
\text { evidence }\end{array}$ & & $5 \%$ & & $24 \%$ & $59 \%$ & $8 \%$ & $3 \%$ & & & & & & & \\
\hline $\begin{array}{l}\text { Statutory } \\
\text { enquiries }\end{array}$ & & & & $17 \%$ & $34 \%$ & $26 \%$ & $20 \%$ & & $3 \%$ & & & & & \\
\hline $\begin{array}{l}\text { Analysis of rental } \\
\text { evidence to } \\
\text { determine rental } \\
\text { value }\end{array}$ & & & & $5 \%$ & $8 \%$ & $8 \%$ & $15 \%$ & $65 \%$ & & & & & & \\
\hline $\begin{array}{l}\text { Analysis of sales } \\
\text { evidence and/ or } \\
\text { other sources to } \\
\text { determine } \\
\text { appropriate } \\
\text { capitalisation rate }\end{array}$ & & & & $5 \%$ & $5 \%$ & $3 \%$ & $8 \%$ & $47 \%$ & $29 \%$ & $3 \%$ & & & & \\
\hline $\begin{array}{l}\text { Analysis of other } \\
\text { relevant data }\end{array}$ & & & & $5 \%$ & $5 \%$ & $2 \%$ & $7 \%$ & $39 \%$ & $7 \%$ & $34 \%$ & & & & \\
\hline $\begin{array}{l}\text { Capital valuation } \\
\text { calculated }\end{array}$ & & & & & & & & & $5 \%$ & $8 \%$ & $88 \%$ & & & \\
\hline Check valuation. & & & & & & & & & & & $15 \%$ & $\mathbf{8 5} \%$ & & \\
\hline $\begin{array}{l}\text { Verbal report to } \\
\text { client }\end{array}$ & & & & & & & & & & & & $8 \%$ & $92 \%$ & \\
\hline $\begin{array}{l}\text { Final report to } \\
\text { client }\end{array}$ & & & & & & & & & & & & & & $100 \%$ \\
\hline
\end{tabular}

The most marked deviation from the expected task sequence was found to be the analysis and scrutiny of legal documentation, including the lease. The majority of valuers reported that this came far later in the sequence, though there was a range of points at which the information became available.

A number of the activities were frequently carried out together or else the tasks overlapped. 
Personnel carrying out tasks

Data from this section was again collected by way of a sheet presented to the interviewees. Along the vertical axis were the 14 task activities identified above. Along the horizontal axis were four classes of surveyor who might have involvement in the tasks. These were in decreasing order of seniority:

- Partners or directors

- Associate (partner or director)

- Qualified surveyor/professional staff

- Graduate level

Table 7: Analysis of sequence of task ordering

\begin{tabular}{|c|c|c|c|}
\hline $\begin{array}{l}\text { Group } \\
\text { sequence }\end{array}$ & Activity & $\begin{array}{l}\text { Mean } \\
\text { score }\end{array}$ & $\begin{array}{c}\text { Modal } \\
\text { class }\end{array}$ \\
\hline 1 & Issue and agreement of instructions & 1.314 & 1 \\
\hline \multirow[t]{2}{*}{2} & Inspection of the property & 2.235 & 2 \\
\hline & Measurement of the property & 2.306 & 2 \\
\hline \multirow[t]{2}{*}{3} & Economic assessment of location & 4.500 & 5 \\
\hline & Collection of comparable evidence & 4.688 & 5 \\
\hline 4 & Statutory enquiries & 5.633 & $5^{5}$ \\
\hline 5 & Analysis/scrutiny of legal documentation & 5.886 & 6 \\
\hline \multirow[t]{3}{*}{6} & $\begin{array}{l}\text { Analysis of rental evidence to determine } \\
\text { rental value }\end{array}$ & 7.333 & 8 \\
\hline & $\begin{array}{l}\text { Analysis of sales evidence and/ or other } \\
\text { sources to determine appropriate } \\
\text { capitalisation rate }\end{array}$ & 7.788 & 8 \\
\hline & Analysis of other relevant data & 8.229 & 8 \\
\hline 7 & Capital valuation calculated & 10.909 & 11 \\
\hline 8 & Check valuation & 11.879 & 12 \\
\hline 9 & Verbal report to client & 12.969 & 13 \\
\hline 10 & Final report to client & 14.000 & 14 \\
\hline
\end{tabular}

They represent the four most common levels of seniority found within surveying practices.

The results are displayed in Figure 2 below. The results show the modal class and the second ranked class for each of the size classifications, small, medium and large (indicated by $\mathrm{S}, \mathrm{M}$ and $\mathrm{L}$ respectively).

\footnotetext{
${ }^{5}$ Although statutory enquiries fall into the same modal class as the two activities above it, it has been grouped as a separate activity as it usually entails a visit to the local authority offices. It physically cannot take place at the same time as the other two activities if carried out by the same personnel.
} 
The figure requires some further explanation as to its construction. The interviewees were allowed to tick more than one box if more than one grade of staff was frequently involved in the activity. This has resulted in the totals of some rows summing to more than 40 . The modal class for each size group has been identified, as has the second ranked group for each class. Displaying all three groups together produces a rather complex diagram, but one that gives a true impression of the range of responses received.

A number of observations can be made about the data. The first is that there are two main patterns superimposed on top of each other. The first is the pattern that exists for small firms where only a small number of people are involved in a valuation. Essentially, the pattern in this case is task completion along the partner/director column. The second pattern is that for medium and large firms, where a much greater degree of delegation takes place. The effect of this is that if medium and larger firms were looked at in isolation, there would be even more emphasis on the degree of delegation. This is illustrated in Figures 2 a-c. This was confirmed by all methods of analysis including the analysis ranking of activity.

Figure 2: Identity of parties most frequently carrying out valuation tasks

\begin{tabular}{|l|c|c|c|c|}
\hline Activity & Partner/Director & Associate & $\begin{array}{c}\text { Qualified } \\
\text { Surveyor/ } \\
\text { Professional } \\
\text { Staff }\end{array}$ & Graduate \\
\hline Issue and agreement of instructions & $\mathbf{3 2}$ & $\mathbf{2 1}$ & 4 & 1 \\
\hline Inspection of the property & 16 & 18 & $\mathbf{2 6}$ & $\mathbf{2 0}$ \\
\hline Measurement of the property & 10 & 16 & $\mathbf{2 5}$ & $\mathbf{2 3}$ \\
\hline Economic assessment of location & 9 & $\mathbf{1 7}$ & $\mathbf{2 3}$ & $\mathbf{1 7}$ \\
\hline Collection of comparable evidence & 8 & 4 & $\mathbf{2 3}$ & $\mathbf{2 6}$ \\
\hline Statutory enquiries & 8 & 2 & $\mathbf{2 2}$ & $\mathbf{2 7}$ \\
\hline $\begin{array}{l}\text { Analysis/scrutiny of legal } \\
\text { documentation }\end{array}$ & 16 & 17 & $\mathbf{2 6}$ & $\mathbf{1 9}$ \\
\hline $\begin{array}{l}\text { Analysis of rental evidence to } \\
\text { determine rental value }\end{array}$ & 12 & 15 & $\mathbf{2 3}$ & $\mathbf{2 2}$ \\
\hline $\begin{array}{l}\text { Analysis of sales evidence and/ or } \\
\text { other sources to determine appropriate } \\
\text { capitalisation rate }\end{array}$ & 14 & 16 & $\mathbf{2 1}$ & $\mathbf{1 8}$ \\
\hline Analysis of other relevant data & 12 & 16 & $\mathbf{2 1}$ & $\mathbf{1 8}$ \\
\hline Capital valuation calculated & $\mathbf{1 7}$ & 14 & $\mathbf{2 3}$ & 16 \\
\hline Check valuation. & $\mathbf{2 8}$ & $\mathbf{1 9}$ & 16 & 0 \\
\hline Verbal report to client & $\mathbf{3 5}$ & $\mathbf{1 8}$ & 16 & 0 \\
\hline Final report to client & $\mathbf{3 2}$ & $\mathbf{1 6}$ & 14 & 7 \\
\hline
\end{tabular}

This is the second major factor to be identified; i.e. the significant degree of delegation from the senior to the more junior members of the firm in the middle parts of the valuations. This will have significance in a number of areas; for 
example, in valuation opinion forming, the quality of the checking process and as regards the level of market knowledge of the senior valuation surveyors. This will be discussed further below.

The distribution of responses was analysed using Chi-square analysis to see if the differences were significant. The results illustrated (critical value for $X^{2}$ at the $5 \%$ level was 12.592 for all the sample ( 6 degrees of freedom) and 7.815 for the paired groups ( 3 degrees of freedom)) that the distribution of results for small firms is significantly different in the central part of the valuation for small firms from the other two groups. There was no significant difference between the conduct of the valuation between medium and large firms.

Figure 2a: Identity of parties most frequently carrying out valuation tasks small firms

\begin{tabular}{|l|c|c|c|c|}
\hline Activity & $\begin{array}{c}\text { Partner/ } \\
\text { Director }\end{array}$ & Associate & $\begin{array}{c}\text { Qualified } \\
\text { surveyor/ } \\
\text { professional } \\
\text { staff }\end{array}$ & Graduate \\
\hline Issue and agreement of instructions & $\mathbf{9}$ & 1 & 1 & 0 \\
\hline Inspection of the property & $\mathbf{8}$ & 1 & $\mathbf{6}$ & 4 \\
\hline Measurement of the property & $\mathbf{5}$ & 1 & $\mathbf{5}$ & 4 \\
\hline Economic assessment of location & $\mathbf{6}$ & 1 & $\mathbf{5}$ & 4 \\
\hline Collection of comparable evidence & $\mathbf{7}$ & 0 & $\mathbf{6}$ & $\mathbf{6}$ \\
\hline Statutory enquiries & $\mathbf{7}$ & 1 & $\mathbf{5}$ & 4 \\
\hline Analysis/scrutiny of legal documentation & $\mathbf{8}$ & 1 & $\mathbf{6}$ & 5 \\
\hline $\begin{array}{l}\text { Analysis of rental evidence to determine } \\
\text { rental value }\end{array}$ & $\mathbf{7}$ & 2 & $\mathbf{5}$ & 4 \\
\hline $\begin{array}{l}\text { Analysis of sales evidence and/ or other } \\
\text { sources to determine appropriate } \\
\text { capitalisation rate }\end{array}$ & $\mathbf{7}$ & 0 & $\mathbf{3}$ & $\mathbf{3}$ \\
\hline Analysis of other relevant data & $\mathbf{6}$ & 1 & $\mathbf{4}$ & 3 \\
\hline Capital valuation calculated & $\mathbf{9}$ & 1 & $\mathbf{5}$ & 3 \\
\hline Check valuation. & $\mathbf{7}$ & 0 & $\mathbf{5}$ & 0 \\
\hline Verbal report to client & $\mathbf{1 2}$ & 0 & $\mathbf{6}$ & 0 \\
\hline Final report to client & $\mathbf{9}$ & 0 & $\mathbf{7}$ & 3 \\
\hline
\end{tabular}

\section{Consultation carried out during valuations}

Data on this section was collected in a similar manner to the two preceding sectors. Along the vertical axis were the 14 task activities identified above. Along the horizontal axis were six different possible sources of consultation. Again, the interviewees were asked to indicate whether the parties were always (A), frequently $(\mathrm{F})$, sometimes $(\mathrm{S})$, or never $(\mathrm{N})$ consulted during the conduct of a typical valuation. Consultation was further defined as a party with which the valuer would specifically discuss elements of the valuation of the property with, as opposed to merely collecting evidence from them. 
Figure 2b: Identity of parties most frequently carrying out valuation tasks -medium firms

\begin{tabular}{|c|c|c|c|c|}
\hline Activity & $\begin{array}{l}\text { Partner/ } \\
\text { Director }\end{array}$ & Associate & $\begin{array}{l}\text { Qualified } \\
\text { surveyor/ } \\
\text { professional } \\
\text { staff } \\
\end{array}$ & Graduate \\
\hline Issue and agreement of instructions & 15 & 14 & 2 & 0 \\
\hline Inspection of the property & 5 & 10 & 12 & 12 \\
\hline Measurement of the property & 2 & 9 & 12 & 15 \\
\hline Economic assessment of location & 2 & 9 & 12 & 10 \\
\hline Collection of comparable evidence & 1 & 3 & 13 & 12 \\
\hline Statutory enquiries & 1 & 1 & 12 & 15 \\
\hline Analysis/scrutiny of legal documentation & 4 & 9 & 12 & 9 \\
\hline $\begin{array}{l}\text { Analysis of rental evidence to determine } \\
\text { rental value }\end{array}$ & 4 & 7 & 12 & 14 \\
\hline $\begin{array}{l}\text { Analysis of sales evidence and/ or other } \\
\text { sources to determine appropriate } \\
\text { capitalisation rate }\end{array}$ & 4 & 9 & 12 & 13 \\
\hline Analysis of other relevant data & 4 & 9 & 11 & 12 \\
\hline Capital valuation calculated & 4 & 10 & 13 & 9 \\
\hline Check valuation. & 15 & 12 & 7 & 0 \\
\hline Verbal report to client & 14 & 12 & 6 & 0 \\
\hline Final report to client & 15 & 12 & 6 & 4 \\
\hline
\end{tabular}

Figure 2c: Identity of parties most frequently carrying out valuation tasks large firms

\begin{tabular}{|c|c|c|c|c|}
\hline Activity & $\begin{array}{l}\text { Partner/ } \\
\text { Director }\end{array}$ & Associate & $\begin{array}{c}\text { Qualified } \\
\text { surveyor/ } \\
\text { professional } \\
\text { staff }\end{array}$ & Graduate \\
\hline Issue and agreement of instructions & 8 & 6 & 1 & 1 \\
\hline Inspection of the property & 3 & 7 & 8 & 4 \\
\hline Measurement of the property & 3 & 6 & 8 & 4 \\
\hline Economic assessment of location & 1 & 7 & 6 & 4 \\
\hline Collection of comparable evidence & 0 & 1 & 4 & 8 \\
\hline Statutory enquiries & 0 & 0 & 5 & 8 \\
\hline Analysis/scrutiny of legal documentation & 4 & 7 & 8 & 5 \\
\hline $\begin{array}{l}\text { Analysis of rental evidence to determine } \\
\text { rental value }\end{array}$ & 1 & 6 & 6 & 4 \\
\hline $\begin{array}{l}\text { Analysis of sales evidence and/or other } \\
\text { sources to determine appropriate } \\
\text { capitalisation rate }\end{array}$ & 3 & 7 & 6 & 3 \\
\hline Analysis of other relevant data & 2 & 6 & 6 & 3 \\
\hline Capital valuation calculated & 4 & 3 & 5 & 4 \\
\hline Check valuation. & 6 & 7 & 4 & 0 \\
\hline Verbal report to client & 7 & 6 & 4 & 0 \\
\hline Final report to client & 8 & 4 & 1 & 0 \\
\hline
\end{tabular}


The ability to distinguish between the frequency of consultation was unproven and the results have been assessed according to the simple frequency of occurrence. The results are presented in Figure 3 below.

Five major clusters of consultation can be identified (see Table 8):

Table 8: Major points of consultation and an identification of the parties involved in the consultation

\begin{tabular}{|c|c|c|}
\hline Number & Stage in valuation & $\begin{array}{l}\text { Parties consulted by valuer } \\
\text { (in order of decreasing } \\
\text { intensity of consultation) }\end{array}$ \\
\hline $\mathrm{CP} 1$ & $\begin{array}{l}\text { At time of } \\
\text { instruction }\end{array}$ & $\begin{array}{ll} & \text { Partner/Director } \\
\text { - } & \text { Client }\end{array}$ \\
\hline $\mathrm{CP} 2$ & $\begin{array}{l}\text { Collection of } \\
\text { comparable } \\
\text { evidence }\end{array}$ & $\begin{array}{ll}\text { - } & \text { Letting agents within } \\
& \text { firm } \\
\text { - } & \text { Investment agents within } \\
& \text { firm } \\
\text { - } & \text { Other valuers within firm } \\
\end{array}$ \\
\hline $\mathrm{CP} 3$ & $\begin{array}{l}\text { Analysis of rental } \\
\text { and sale evidence }\end{array}$ & $\begin{array}{ll}\text { - } & \text { Investment agents within } \\
\text { firm } \\
\text { - Letting agents within } \\
\text { firm }\end{array}$ \\
\hline$\overline{\mathrm{CP} 4}$ & $\begin{array}{l}\text { Checking of } \\
\text { valuation }\end{array}$ & $\begin{array}{ll}\text { - } & \text { Other valuers within firm } \\
\text { - } & \text { Partner/director }\end{array}$ \\
\hline CP5 & $\begin{array}{l}\text { Verbal report to } \\
\text { client }\end{array}$ & - $\quad$ Client \\
\hline
\end{tabular}

It can be noted that much of the consultation is internal to the firm. The main source of external consultation is with the client himself or herself. A second observation is that there are very few points of very significant levels of consultation $^{7}$; indeed the overall level of consultation seemed low. Of the two "very significant" points, one was found right at the end of the process at the point in which the valuation is checked.

\footnotetext{
${ }^{6}$ At significant level or above.

${ }^{7}$ In the case of this section, the classification was as follows: Very Significant Level of Consultation, $>20$ mentions, Significant level of Consultation, 10-19 mentions, Some Consultation, 5-9 mentions, and Peripheral, 0-4 mentions.
} 


\section{DISCUSSION AND CONCLUSIONS}

The three components of this section that have examined the way valuations are conducted have provided an insight into the complexity of this process. A typical commercial valuation is rarely a simple task carried out by a single valuer. In large and medium sized firms in particular, a valuation can be seen to be a complex team effort, albeit overseen by one or a small team of managers. The sequence in which a valuation is constructed has common features, but is by no means uniform. The personnel involved in some of the key valuation tasks may well not be those who are responsible for completing and signing off the final valuation. There are key points in the process where the valuer in charge consults, receives opinions of others and tests his or her own opinion about the property. The result of the combination of all of these aspects of the process is the final valuation. 

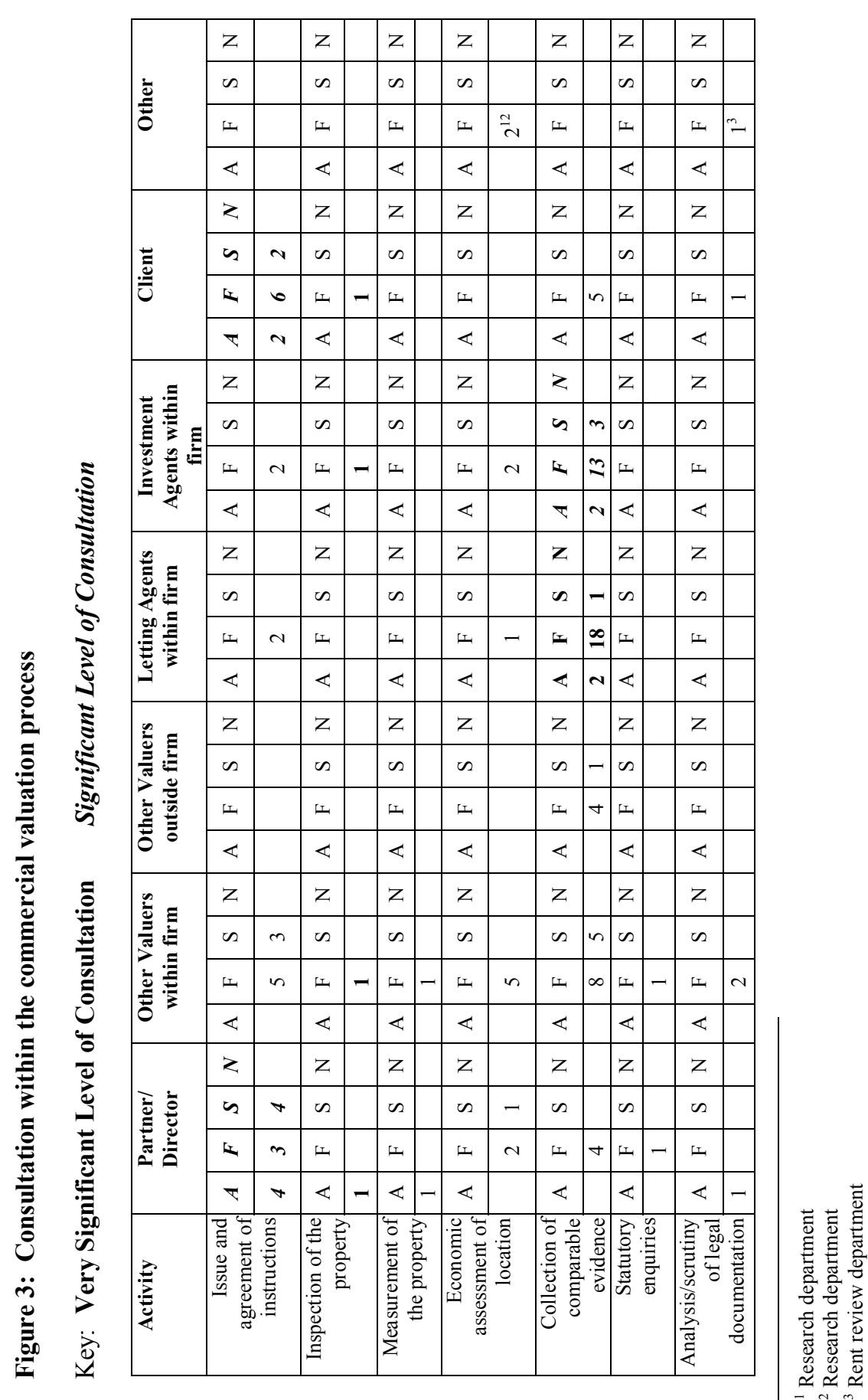

Pacific Rim Property Research Journal, Vol 11, No 1 


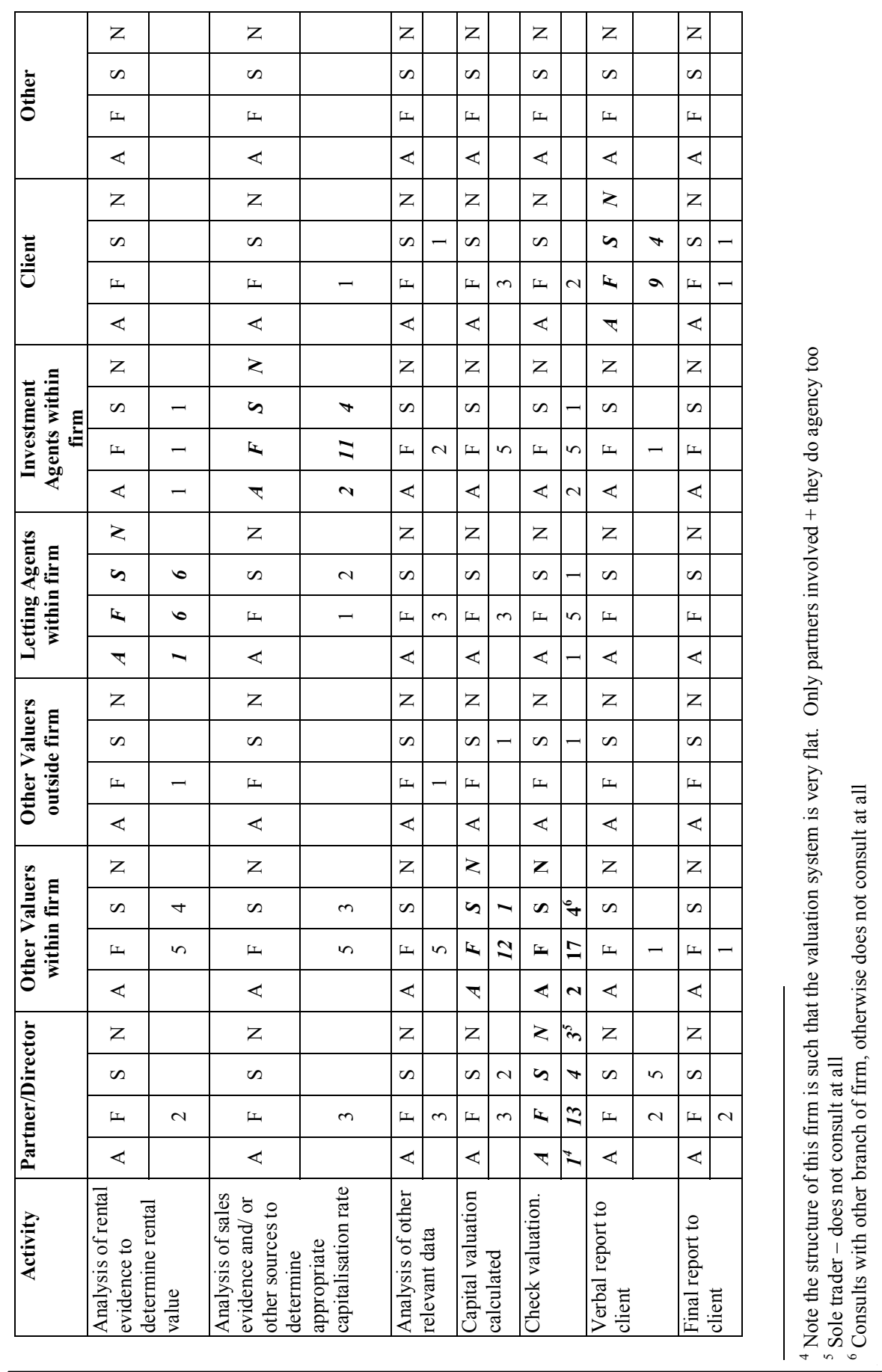


To many valuers, these findings will come as no surprise, although no research has actually been published to date on these issues. These matters do need careful consideration in the context of future behavioural studies. Many previous studies have assumed valuations to be carried out by a single individual working in a uniform environment. It is clear from this work that many, if not the majority of commercial valuations, are carried out in very complex environments involving the interaction of many individuals whose status is not uniform. These interactions and this process need to be modelled and considered in future behavioural studies. These observations apply not only to valuation practice in the UK, where the study was undertaken but also to all markets where commercial valuation work is undertaken. There is opportunity for cross-cultural studies to be undertaken, particularly in mature property markets such as the USA, Canada, Australia and New Zealand.

Starting with the task sequence, there is little in the findings that is surprising. The exception is the analysis and scrutiny of the legal documentation, which includes the lease, that takes place far later in the process than might be expected. This is apparently due usually to time pressure in most single valuation instructions that results in valuers having to commence their work before all of the information is received. It can be noted that the property is inspected and measured before any evidence is collected.

The question of the personnel who carry out the key tasks in a valuation is a rather more difficult one for studies of behaviour. Most of the theories concerned with this area are based around the individual as a decision-maker, as are the other studies in real estate and other professional work such as auditing. The reality of commercial valuation practice in the $\mathrm{UK}$ is that the process involves a complex interaction of players and information flows. The practice observed and the procedures put in place by the valuation firms effectively means that it is usual for one valuer to be responsible for the production of a valuation, even though many of the tasks are actually delegated to less senior members of the firm. It is the behaviour of this senior valuer that is the key in the majority of cases, but the complex interaction of personnel and data requires careful consideration in an analysis of behaviour and its effect on the outcome of a valuation. This is perhaps the key finding of this research and one that future researchers in this field must consider.

In the practical field of valuation and its reliability, a number of observations can be made that suggest future avenues for research. For example, it is possible that the risk of bias might be increased by the pattern of delegation observed. The valuers who are either responsible for the valuation or are responsible for checking the valuation produced by another under the procedural protocol are actually remote from the bulk of the process. The partners and directors can be seen to be fulfilling a strategic role, with emphasis being on liaison with clients and in quality control.

Pacific Rim Property Research Journal, Vol 11, No 1 
The problem with this role is that these parties will be remote from the market and detailed knowledge of transactions. This reduces the ability to screen unsupportable value judgements. In addition, partners' and directors' opinions have greater weight than those of other members of the team, meaning that their will is likely to dominate. If the partners' opinion itself is erroneous, an otherwise correct valuation might be rejected. The question of client influence and potential bias can be seen to be a potential issue. All of these factors can be seen to require further investigation in future.

Further down the seniority scale, valuations carried out by associates show a similar pattern. There is delegation at associate level to the two lower grades of key tasks, including measurement and inspection, but in particular in the gathering of comparable evidence, the point at which the value opinion can be challenged by the weight of evidence.

This is the situation that exists mainly with large and medium sized firms. With small firms, the position is slightly different. Senior, more experienced staff, tend to have a closer involvement throughout the valuation process than with the larger firms. However, these valuers also have less opportunity to consult and to expose their opinions of value to others.

The true significance of these findings are not within this paper itself, but are found within the uses that subsequent researchers make of them. Commercial valuation is a complex process which is not easy to replicate experimentally. Experiments or simulated valuations are, however, a common way of exploring the influence of behaviour on the outcome of valuations. The findings of this research should assist greatly in designing experiments whose results should be of significance to the valuation profession. There are also a number of research avenues suggested by the research that are concerned with the dynamics of the process and the interaction of the participants within the process. A fuller understanding of this process as a whole will act to improve the quality of the output of the process as a whole.

\section{REFERENCES}

Ashton, A. and Ashton, R. (1988), Sequential belief revision in auditing. The Accounting Review LXIII (4), pp. 623-41.

Assere, S. (1992), The auditors going concern decision: interaction of task variables and the sequential processing of evidence. The Accounting Review, 87(2), April.

Baum, A., Crosby, N., Gallimore, P., McAllister, P. and Gray, A. (2000), The role and influence of valuations in commercial property investment markets. RICS Research Foundation Report, RICS: London. 
Baum. A., Mackmin, D. and Nunnington, N. (1998), The Income Approach to Property Valuation, $4^{\text {th }}$ edition, Thomson, London.

Diaz III, J. (1997), An investigation into the impact of previous value estimates on appraisal judgement. Journal of Real Estate Research, 13(1), pp. 57-66.

Diaz, J., Gallimore, P. and Levy, D. (2000), Residential valuation behaviour in the United States, the United Kingdom, and New Zealand. Paper presented to the RICS Cutting Edge Property Research Conference, London.

Gallimore, P. and Wolverton, M. (1997), Price-knowledge induced bias: a cross cultural comparison. Journal of Property Valuation and Investment, 15(3), pp. 274281.

Havard, T. (2002), Valuation Reliability and Valuer Behaviour. RICS Foundation FiBRE Report.

Hogarth, R. and Einhorn, H. (1992), Order effects and belief updating: the belief adjustment model. Cognitive Psychology, 24(1), pp. 1-55.

Krull, G., Reckers, P. and Wong-on-Wing, B. (1993), The effect of experience, fraudulent signals and information presentation order on auditors beliefs. Auditing, $12(2)$.

Messier, W. (1992), The sequence of audit evidence: its impact on the extent of audit testing and report formulation. Accounting and Business Research, 22, pp. 86 -95 .

Miles, M. and Huberman, A. (1984), Qualitative Data Analysis: A Sourcebook of New Methods. London, Beverly Hills: Sage.

Newell, A. and Simon, H. (1972), Human Problem Solving. Prentice Hall, New Jersey.

RICS (2003), The Valuation and Appraisal Standards. RICS, London.

Tubbs, R., Messier, W. and Knechel, R. (1990), Recency effects in the auditors belief revision process. The Accounting Review, 65(2), April.

Pacific Rim Property Research Journal, Vol 11, No 1 